\title{
Recognition of drug related problems by home healthcare employees: A Dutch observational study with self reports
}

\author{
Carolien GM Sino, Ad A Dooren, van, Annemarie M Haverkamp, Marieke J Schuurmans \\ Research Centre for Innovation in Healthcare, University of Applied Sciences Utrecht, the Netherlands.
}

Correspondence: Carolien GM Sino. Address: University of Applied Sciences Utrecht, Research Centre for Innovation in Healthcare, the Netherlands. P.O. Box 85182, AD Utrecht. Email: Carolien.sino@hu.nl.

Received: October 7, 2012

Accepted: November 26, 2012

Online Published: January 22, 2013

DOI : $10.5430 /$ jnep.v3n8p41

URL: http://dx.doi.org/10.5430/jnep.v3n8p41

\section{Abstract}

Background: In the Netherlands, the majority ( $80 \%$ ) of the older people (age $>65$ ) do use prescribed drugs. $82 \%$ of the patients who receive home healthcare are 65 years of age or older. Because of natural changes in age-related drug metabolism, these older home healthcare patients are particularly vulnerable to drug-related problems.

Purpose: To describe how home healthcare Nurse Assistants (NA), home healthcare Licensed Practical Nurses (LPN) and home healthcare Registered Nurses $(\mathrm{RN})$ rate their knowledge, monitoring skills and ability to recognize adverse drug reactions and drug interactions of the most commonly used medication in older people, aged 75 or older, in the Netherlands.

Methods: A survey design was conducted with the use of a questionnaire in a home care organization in the Netherlands.

Results: Home healthcare workers most easily recognize side-effects of confusion, drowsiness and fatigue more easily than gastrointestinal disorders and dizziness. In addition, home healthcare Registered Nurses and home healthcare Licensed Practical Nurses were more likely than home healthcare assistants to recognize and report symptoms due to sideeffects.

Conclusion: There are differences between RN, LPN and NA in the knowledge and their skills to recognize adverse drug reactions and interactions in home care. Consequently, the allocation of clients to RNs, LPNs or NAs should be arranged well. Home healthcare workers are well positioned to act preventatively and alertly to potential drug related problems, if they have adequate access to information on side effects and interactions of medication.

\section{Key words}

Home care, Drug related problem, Recognition, Side effect, Interaction

\section{Background}

It is a well-known fact that the proportion of the population that is 65 years or older is rapidly increasing. The older population more frequently suffers from multimorbidities, use more medication and are treated by a larger number of health care professionals than the younger population ${ }^{[1]}$. In the Netherlands drug consumption is three times higher among persons of 65 years or older, while people aged 75 years or older consume five times more than the average person ${ }^{[2]}$. Because of natural changes in age-related drug metabolism, older people are particularly vulnerable to medication-related problems ${ }^{[3]}$. Due to ageing, shorter hospital stays and an emphasis on outpatient care, the number of older persons 
receiving home healthcare is growing ${ }^{[4]}$. Therefore, Drug Related Problems (DRPs) are an increasing challenge in homecare organizations as described by Meredith et al. ${ }^{[5]}$ and Parsons et al. ${ }^{[6]}$.

Home healthcare workers help seniors to live independently as long as possible, given the limits of their medical condition. They cover a wide range of services such as help with bathing and getting dressed or intravenous therapy and injections, wound care, education on disease treatment or assistance with medication intake. Because of this wide range of services home healthcare workers are divided by their education level and corresponding responsibility into: Registered (home healthcare) Nurses (RNs), Licensed Practical Nurses (LPNs), Nurse Assistants (NA) and Housekeepers.

The differences between educational levels are determined by the degree of responsibilities, the level of complexity and the degree of transfer. The latter indicates the degree to which the professional is able to apply his or her knowledge and skills to different situations ${ }^{[7]}$. Medication is not part of the education for NAs. However, despite their lack of education in medication, NAs work with increasingly older clients using many drugs. For Dutch LPNs and RNs, medication education is part of their training.

In addition to the general practitioner and pharmacist, home healthcare workers, who visit their clients in their homes on a regular basis, may be able to help in early recognition of potential DRPs. Several authors stated that nurses play an important role in patient medication safety ${ }^{[8-11]}$. In their roles as caregivers, educators and administrators of medications, home healthcare Registered Nurses and Licensed Practical Nurses are particularly well positioned to be the most astute observers of adverse drug reactions ${ }^{[12,13]}$. Notwithstanding the fact that homecare employees are in the right position to observe adverse drug reactions, it depends on their knowledge and self efficacy how they act in actual practice. Selfefficacy is defined as a person's belief to succeed in certain situations and can be viewed as the level of one's competence to complete tasks and to reach goals ${ }^{[14]}$.

According to Meredith and colleagues ${ }^{[5]}$ nearly one-third of the home healthcare patients surveyed $(n=6,718)$ had evidence of a potential medication problem or were taking a drug considered inappropriate for older people. Ellenbecker et al. ${ }^{[15]}$ showed that more than three quarters of a homecare patient population $(\mathrm{n}=1467)$ were at risk for medication errors as a result of taking five or more different drugs.

Currently, for economic reasons and changes in the reimbursement of homecare, home healthcare nurses have often been replaced by less educated nurse assistants ${ }^{[16,17]}$. Medication, preventive tasks like patient education about their medication or early recognition of medication related problems, are not part of the education of the NAs.

In this study, we assessed whether home care workers with different educational degrees are aware of, recognize and report (potential) Drug Related Problems and if so, what they subsequently do about them.

\section{Purpose of the study}

This paper reports a study describing how home healthcare Nurse Assistants, home healthcare Licensed Practical Nurses and home healthcare Registered Nurses rate their knowledge, monitoring skills and ability to recognize adverse drug reactions and drug interactions of the most commonly used medication in older people, aged 75 or older, in the Netherlands.

\section{Methods}

\subsection{Study Design}

A survey was conducted using a questionnaire to answer the following research questions: 
- How do home healthcare workers rate their knowledge, monitoring skills and ability to recognize adverse drug reactions and interactions in their patients?

- What are the differences between home healthcare nurses, home healthcare licensed practical nurses and home healthcare nurse assistants with regards to recognizing adverse drug reactions and interactions?

\subsection{Respondents}

The study population consisted of 280 home healthcare employees (divided between five geographic areas) of a large home care organization in the Netherlands. A convenience sample from the home healthcare workers was recruited. Respondents voluntarily took part in the study, which was presented and explained during a regular team meeting. The one inclusion criterion for participation in the study was that the home healthcare worker were employed in a direct patient care position for at least eight hours per week.

\subsection{I nstruments}

To gain insight in how home healthcare workers rate their knowledge, monitoring skills and ability to recognize adverse drug reactions and interactions, a questionnaire was developed. Starting point for this questionnaire was the potential side effects of the ten most frequently used drug products by people aged 75 years or older, according to the Dutch Foundation for Pharmaceutical Statistics (SKF, 2003) (see Table 1). Subsequently, from these ten most common drugs, the potential side-effects were divided in three categories: 1) gastrointestinal (GI) side effects such as diarrhea and nausea, 2) central nervous system (CNS) side effects such as confusion, drowsiness and fatigue and 3) dizziness. For each category, ten questions graded on a five point Likert-scale (from 1-strongly agree to 5-strongly disagree) were asked about respondents' knowledge and recognition of side-effects, the home healthcare worker's responsibility to discover the side-effects and her responsibility to report them to general practitioners (GPs) or pharmacists.

Table 1. Top 10 medicines most commonly used by persons $75+$

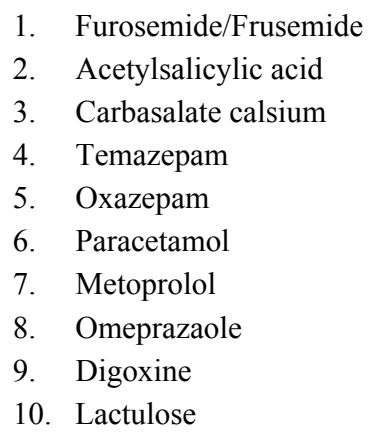

\subsection{Validation of the questionnaire}

To establish face validity, the questionnaire was assessed by a nursing scientist and a staff member of the home care organization. Subsequently, a panel of two expert pharmacists judged the questionnaire. Finally, the feasibility of the questionnaire was discussed during a national congress of home healthcare services by 76 home healthcare nurses and 3 home healthcare licensed practical nurses. Based on the feedback from the pharmacists and the reactions of the home healthcare workers, the questionnaire was slightly adjusted.

\subsection{Description of the questionnaire}

The questionnaire started with two filter questions to select only participants who met the inclusion criteria of regular patient contact and at least eight working hours a week. The questionnaire included an introduction asking for demographic characteristics such as function, work experience in home healthcare in years, and actual working hours per 
week. Because of the small size of some teams within the healthcare organization and to guarantee anonymity, there were no questions about age or the team the respondent was working in. After the two filter questions, seven equal questions were asked per side effect category. Finally, there was one open question about possible tools that could support home healthcare workers' early recognition of (potential) side-effects and interactions.

\subsection{Data collection}

The questionnaire was distributed to 25 teams within the home care organization. All home healthcare workers were informed about the study by means of the home care organization newsletter. Eleven teams received the questionnaire through internal mail and arranged for internal distribution themselves. In fourteen teams, the questionnaires were personally distributed and orally explained by the independent researcher. There was no relation between the researcher and the home care organization. In total, 280 questionnaires were distributed between December 2009 and January 2010.

\subsection{Ethical considerations}

In this study, perceptions of home healthcare workers have been described about their daily practice. Permission from an ethics committee was not required. Participation was entirely voluntary. All participants were extensively informed about the study through a written introduction. The anonymity of the respondents was guaranteed, and it was not possible to trace the answers back to the participant. The data obtained from the participants was used only for this study. Consent was assumed through the participants' completion of the questionnaire. Participants were informed that all findings would be reported as group results and would be submitted for publication. Confidentiality was ensured through the use of code numbers to guarantee anonymity of the respondents.

\subsection{Data analysis}

Data were analyzed using SPSS for windows version 18.0. Descriptive statistics with frequencies and percentages were used to answer the research questions. Logistic regression was used because of a binary (yes/no) dependent variable to better understand the differences between home healthcare employees who agreed to the statements and who did not.

\section{Results}

\section{Characteristics of the respondents}

Almost $40 \%$ of the 280 home healthcare workers who received the questionnaire responded positively ( $\mathrm{n}=107)$. The respondents were divided as follows: $25 \%$ home healthcare Registered Nurses ( $\mathrm{n}=26), 41 \%$ home healthcare Licensed Practical Nurses $(n=43)$ and $34 \%$ home healthcare Nurse Assistants $(n=36)$. Two respondents did not answer the question about their job function and were excluded (see Table 2). Table 3 demonstrates the stated knowledge, reporting actions and respondents ability to recognize gastrointestinal disorders (1), confusion, drowsiness and fatigue (2) and dizziness (3) per care giver level. The homecare workers were poorly informed about medication changes of their patients.

Home healthcare Registered Nurses recognized more $(\mathrm{OR}=3.84 ; \mathrm{CI}=1.43-10.30)$ gastrointestinal disorders, diarrhea and nausea (see Table 4) and also more $(\mathrm{OR}=4.33 ; \mathrm{CI}=1.09-17.26)$ confusion, drowsiness and fatigue than home healthcare assistants. In addition, home healthcare Registered Nurses stated more often $(\mathrm{OR}=4.44 ; \mathrm{CI}=1.10-17.03)$ than home healthcare assistants that they know that confusion, drowsiness and fatigue could be adverse drug reactions (see Table 5). Respondents mentioned the following tools that could support the early recognition of (potential) side-effects and interactions: (1) information about side-effect and interaction in a handy pocketbook, (2) medication training on a structural basis and (3) information provided by the pharmacist. 
Table 2. Characteristics of the Respondents $(n=107)$

\begin{tabular}{lll}
\hline & N & \% \\
\hline Function & 26 & 24.3 \\
Home Healthcare Registered Nurse & 26.2 & 40.2 \\
Home Healthcare Licensed Practical Nurse & 43 & 33.6 \\
Home Healthcare Nurse Assistant & 36 & 1.9 \\
Missing & 2 & \\
Work experience in years & 18 & 16.8 \\
$0-5$ & 23 & 21.5 \\
$6-10$ & 17 & 15.9 \\
$11-10$ & 46 & 43 \\
$>16$ & 3 & 2.8 \\
Missings & & \\
Working hours per week & 13 & 12.1 \\
$9-16$ & 30 & 28 \\
$17-24$ & 56 & \\
$>25$ & 8 & \\
Missings & 5.3 & \\
\hline
\end{tabular}

Table 3. Recognition of side-effects

\begin{tabular}{|c|c|c|c|c|c|c|}
\hline \multirow{2}{*}{ Recognition of } & \multicolumn{2}{|l|}{$\mathbf{R N}^{*}$} & \multicolumn{2}{|l|}{$\mathbf{L P N}^{* *}$} & \multicolumn{2}{|l|}{ NA*** } \\
\hline & $\mathbf{N}$ agree & \% agree & $\mathbf{N}$ agree & $\%$ agree & $\mathbf{N}$ agree & \% agree \\
\hline gastrointestinal disorders, diarrhea, nausea & $\mathbf{n}=\mathbf{2 5}$ & & $n=42$ & & $\mathbf{n}=\mathbf{3 3}$ & \\
\hline I do know that these complaints could be side effects & 23 & 92.0 & 35 & 83.3 & 27 & 81.8 \\
\hline I always report these complaints & 24 & 96.0 & 38 & 90.5 & 27 & 81.8 \\
\hline My colleagues always report these complaints & 9 & 36.0 & 24 & 57.1 & 15 & 45.5 \\
\hline I do recognize these complaints from the nursing report & 13 & 52.0 & 27 & 64.3 & 20 & 60.6 \\
\hline Clients always indicate these complaints to me & 5 & 20.0 & 6 & 26.2 & 11 & 33.3 \\
\hline It is my task to ask further about these kinds of complaints & 25 & 100.0 & 40 & 95.2 & 29 & 87.9 \\
\hline I do contact the general practitioner about these complaints & 18 & 72.0 & 30 & 71.4 & 12 & 36.6 \\
\hline I do contact the pharmacist about these complaints & 7 & 28.0 & 22 & 52.4 & 7 & 21.2 \\
\hline I do recognize these complaints in my daily practice & 23 & 92.0 & 37 & 88.1 & 23 & 63.9 \\
\hline I do know that these complaints could be side effects & 23 & 92.0 & 40 & 95.2 & 27 & 75.0 \\
\hline I always report these complaints & 25 & 100.0 & 37 & 88.1 & 25 & 69.4 \\
\hline My colleagues always report these complaints & 8 & 32.0 & 23 & 95.2 & 15 & 41.7 \\
\hline I do recognize these complaints from the nursing report & 11 & 44.0 & 30 & 71.4 & 20 & 55.6 \\
\hline Clients always indicate these complaints to me & 6 & 24.0 & 5 & 11.9 & 12 & 33.3 \\
\hline It is my task to ask further about these kinds of complaints & 25 & 100.0 & 38 & 90.5 & 27 & 75.0 \\
\hline I do contact the general practitioner about these complaints & 18 & 72.0 & 34 & 81.0 & 10 & 27.8 \\
\hline I do contact the pharmacist about these complaints & 19 & 76.0 & 22 & 52.4 & 6 & 16.7 \\
\hline dizziness & $\mathbf{n}=\mathbf{2 6}$ & & $\mathrm{n}=\mathbf{4 2}$ & & $\mathbf{n}=\mathbf{3 6}$ & \\
\hline I do recognize these complaints in my daily practice & 18 & 69.2 & 30 & 71.4 & 23 & 63.9 \\
\hline I always report these complaints & 22 & 84.6 & 39 & 92.9 & 27 & 75.0 \\
\hline My colleagues always report these complaints & 6 & 23.1 & 23 & 54.8 & 17 & 47.2 \\
\hline I do recognize these complaints from the nursing report & 12 & 46.1 & 28 & 66.6 & 19 & 52.8 \\
\hline Clients always indicate these complaints to me & 7 & 26.9 & 9 & 21.4 & 15 & 41.7 \\
\hline It is my task to ask further about these kinds of complaints & 26 & 100.0 & 40 & 95.2 & 29 & 80.6 \\
\hline I do contact the general practitioner about these complaints & 17 & 68.0 & 31 & 73.8 & 15 & 41.7 \\
\hline I do contact the pharmacist about these complaints & 17 & 68.0 & 22 & 52.4 & 9 & 25.0 \\
\hline
\end{tabular}

${ }^{*} \mathrm{RN}=$ Registered Nurse, ${ }^{* *} \mathrm{LPN}=$ Licensed Practical Nurse $* * * \mathrm{NA}=$ Nurse Assistant 
Table 4. Factors related to the recognition of Drug Related Problems: a logistic regression analyses $(\mathrm{n}=107)$

\begin{tabular}{|c|c|c|c|c|c|c|c|c|c|}
\hline \multirow{2}{*}{ Predictor variable } & \multicolumn{3}{|c|}{ GI, Diarrhea, Nausea } & \multicolumn{3}{|c|}{ Confusion, Drowsiness, Fatigue } & \multicolumn{3}{|c|}{ Dizziness } \\
\hline & OR & CI 95\% & & OR & CI 95\% & & OR & CI 95\% & \\
\hline Nurse Assistant & 1 & ref & & 1 & ref & & 1 & ref & \\
\hline Licensed Practical Nurse & 1.8 & 0.6 & 5.2 & $4.3^{*}$ & 1.1 & 17.3 & 1.3 & 0.4 & 3.7 \\
\hline Registered Nurse & $3.8^{*}$ & 1.4 & 10.3 & $4.2^{*}$ & 1.3 & 13.3 & 1.4 & 0.5 & 3.7 \\
\hline \multicolumn{10}{|l|}{ Experience in years } \\
\hline $0-5$ & 1 & ref & & 1 & ref & & 1 & ref & \\
\hline $6 \quad 10$ & 1.2 & 0.3 & 4.4 & 1.8 & 0.4 & 8.1 & 1.5 & 0.4 & 5.3 \\
\hline $11 \quad 15$ & 1.8 & 0.5 & 7.4 & 0.9 & 0.2 & 4.0 & 1.9 & 0.5 & 7.8 \\
\hline$\geq 16$ & 2.1 & 0.7 & 6.9 & 2.1 & 0.6 & 7.7 & 2.5 & 0.8 & 7.8 \\
\hline \multicolumn{10}{|l|}{ Working hours per week } \\
\hline 916 & 1 & ref & & 1 & ref & & 1 & ref & \\
\hline 1724 & 0.3 & 0.1 & 1.4 & 1.2 & 0.2 & 7.4 & 0.8 & 0.2 & 3.4 \\
\hline$\geq 25$ & 0.6 & 0.2 & 2.5 & 0.7 & 0.1 & 3.8 & 1.1 & 0.3 & 4.1 \\
\hline
\end{tabular}

Note. $\mathrm{OR}=$ Odds Ratio; $\mathrm{GI}=$ Gastrointestinal disorders; Ref $=$ reference

Table 5. Factors related to the knowledge of Drug Related Problems: a logistic regression analyses $(\mathrm{n}=107)$

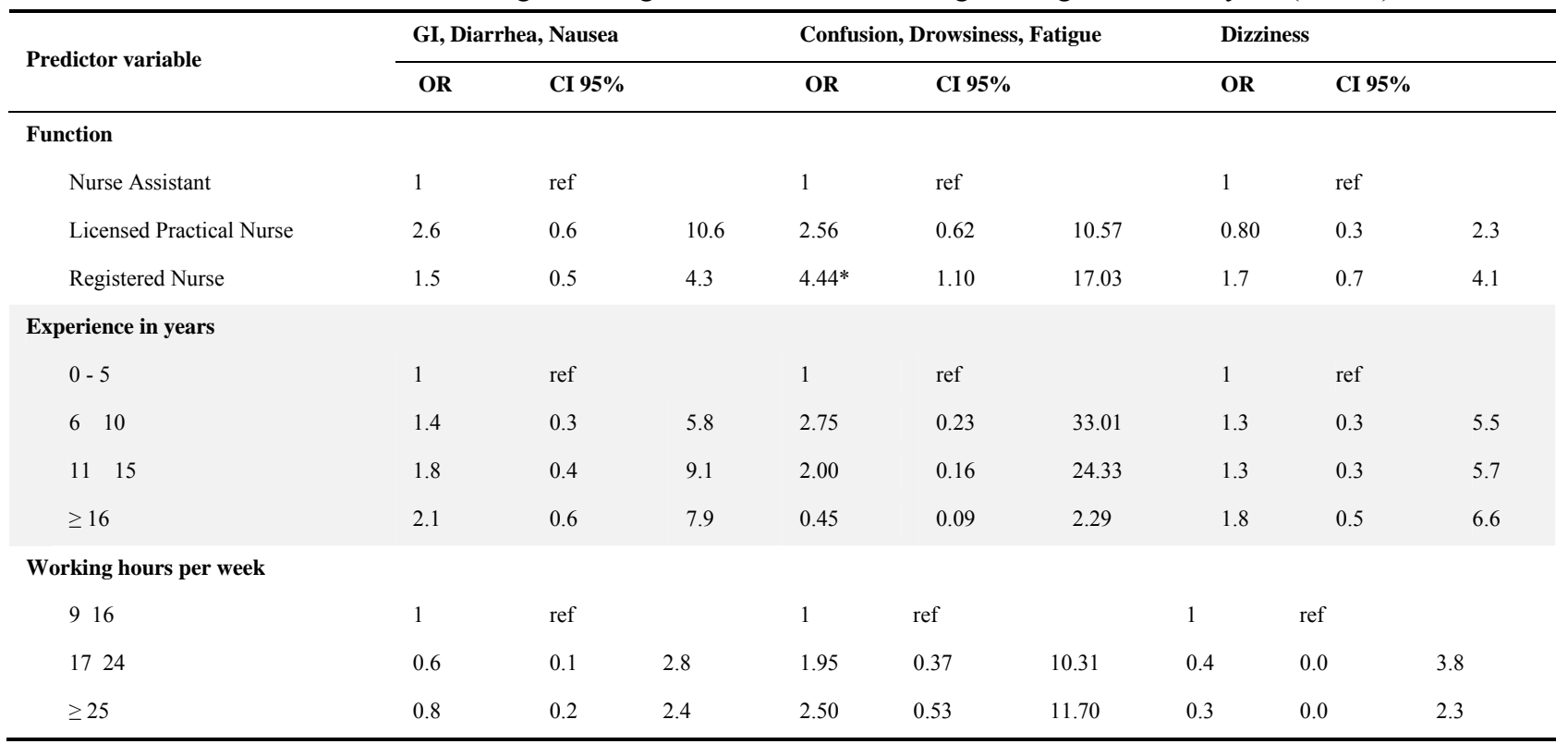

Note. $\mathrm{OR}=$ Odds Ratio; $\mathrm{GI}=$ Gastrointestinal disorders; Ref=reference

\section{Discussion}

This study described how home healthcare workers assessed their own ability to recognize side-effects of the ten most common medications used by people 75 years or older. Although most home healthcare workers stated that they knew that confusion, drowsiness, fatigue, dizziness and gastrointestinal disorders could be side-effects of medicine use, a significantly lower percentage indicated that they recognize these types of complaints in their daily practice. The Central Nervous System (CNS) category (confusion, drowsiness and fatigue) was more often recognized than the gastrointestinal disturbances and dizziness categories. This may be because clients rarely mention their complaints themselves, and it is 
possible that confusion, drowsiness and fatigue are easier to observe than GI disturbances and dizziness. Remarkably, the general practitioner was contacted more often than the pharmacist. It is possible that homecare workers are more familiar with the general practitioner than with the pharmacist. Position (RN, LPN or NA) appeared to be the only related factor to explain knowledge and recognition skills, which implies that years of experience and working hours per week were not related. This could be explained by the fact that positions are based on education level. As expected, due to this education level, Registered Nurses estimated their recognition skills for gastrointestinal disorders higher than Licensed Practical Nurses and Assistant Nurses. There was no significant difference between the three positions in the rating concerning the knowledge of gastrointestinal disorders. This may be because gastrointestinal disorders are the most common adverse drug events and are therefore known by all homecare employees.

It is remarkable that Nurse Assistants report more often that clients mention complaints to them. This could be because of their kind of work (like housekeeping), which implicates a longer time in company of the patient per visit. Besides, a substantial part (20-25\%) of the Nurse Assistants do not regard it as their task to ask further about the complaints of a patient. Although medication is not part of their training, detecting changes in a patient situation certainly is part of their training. The homecare workers were poorly informed about medication changes of their patients. When these employees would be informed about these changes, they would be better able to monitor potential adverse reactions.

Previous studies have shown that even nurses are inadequately prepared and lack sufficient knowledge to be capable of observing and recognizing medication related problems ${ }^{[8,18-20]}$. Lim et al. ${ }^{[21]}$ explained the need to improve nurses' pharmacological knowledge, medication administration and management in healthcare facilities for older people.

\section{Limitations of the study}

To appreciate the present results, a number of aspects need to be discussed regarding the scope and limitations of this study. First, a voluntary survey from one home healthcare organization with 105 respondents cannot be considered representative of all home healthcare workers in the Netherlands. However, this is the first study about knowledge, reporting and ability to recognize Drug Related Problems and interactions of the most common medication in older people. It does provide an in-depth, insiders' view of the perception of the homecare workers and points out the importance of this issue. Second, a response rate of nearly $40 \%$ is not adequate for generalizing to the entire population. Additionally, the questionnaire was developed specifically for this study. By means of an expert panel, only face validity could be guaranteed.

Because home healthcare workers were asked about their perceptions, the respondents may have overestimated or underestimated their recognition abilities, despite their answers being anonymous. In further research, the observation and recognition skills of home healthcare workers should be measured in "real life" instead of by self reports.

This research was based on a 2003 ranking of the ten most common medications used by individuals 75 years or older. Since then, this top-ten list has changed. Acetylsalicylic acid, metoprolol, furosemide, omeprazole and temazepam are still in the top ten, according to the Foundation for Pharmaceutical Statistics, but new medications include simvastatin, pantoprazole, metformin, isosorbidemononitrate and hydrochlorothiazide (SFK. Foundation for Pharmaceutical Statistics 2010). Because of our interest in the recognition ability of homecare workers, we assume this finding did not influence our results. Over the counter (OTC) medications were not taken into account although these drugs could have side-effects and/or interact with prescribed medications as well. Most home care workers stated that they always report the complaints of their clients in their daily report. Remarkably, less than half of the respondents declared that their colleagues always report complaints related to side effects in the daily report. There is a high probability that home healthcare workers overestimate their own reporting actions and underestimate those of their colleagues. Further, less than half of the respondents stated that clients mention their complaints to them. This result suggests that most clients do not speak about 
their complaints. Therefore, the personal observational skills of home healthcare workers are very important in detecting side effects or interactions.

Although other authors have stated that nurses are in a unique position and indeed can contribute to medication safety ${ }^{[12,13,22]}$, only a few have focused on the role of home healthcare workers. Additionally, many solutions to medication problems focus on the pharmacist or general practitioner. Little attention is paid to the role of home care workers regarding medication safety. Ellenbecker and colleagues ${ }^{[15]}$ demonstrated by means of self reporting that nurses in home care were able to report adverse drugs events from medication errors. Our results are consistent with these findings.

Home healthcare employees should be aware of the added value they offer for observing drug-related problems in their patients through accurate reporting of their observations and contacting the physician or pharmacist when an observation of a potential medication-related problem occurs, home healthcare employees can contribute to medication safety in elderly clients.

\section{I mplications for practice}

Home care employees mentioned the following tools that could support the early recognition of (potential) side-effects and interactions: (1) information about side-effects and interactions in a handy pocketbook, (2) medication training on a structural basis and (3) information provided by a pharmacist. These findings can be used in home healthcare practice to help prevent medication-related problems, such as conditions requiring hospital admissions. Home healthcare employees should be aware of their observational value in patients' home environments. Although the respondents in this study stated that they were generally able to recognize most of the common side-effects, continuous enhancement of both observation and reporting skills is necessary. Home healthcare workers should be aware of specific symptoms which could indicate a medication-related problem. These symptoms could function as a "red flag" for potential medication-related problems. Further research is necessary to assess these so called "red flags." Through accurate reporting of their observations and contacting the general practitioner or pharmacist when an observation of a potential medication-related problem occurs, home healthcare employees can contribute to medication safety for elderly clients. Nurse Assistants should be trained and supported in observing changes in home care situations and educated in reporting their findings to the responsible Registered Nurse.

\section{Conclusion and recommendations}

Home healthcare workers stated that they recognized the CNS side-effects category (confusion, drowsiness and fatigue) better than gastrointestinal disorders and dizziness, although home healthcare Registered Nurses and home healthcare Licensed Practical Nurses were more likely to recognize and report symptoms than home healthcare assistants. These results lead to the following recommendations: (1) ensure comprehensive and easy to use information about medication, side-effects and interactions for the several jobs in home healthcare; (2) arrange clear job descriptions regarding medication management; (3) emphasize the importance of complete reporting without delay; (4) provide training and tools for the early recognition of medication-related problems; (5) implement good collaboration between the general practitioner, the pharmacist and the home healthcare organization and make clear communication agreements. Lastly, (6) appoint a Registered Nurse as coordinator for the pharmaceutical care within the home care organization.

This is de first study about the knowledge, reporting and ability to recognize Drug Related Problems and interactions of the most commonly used medication in older people in the Netherlands by home healthcare employees. This first study points out the importance of the theme as we discussed. Therefore, further research is certainly needed. 


\section{References}

[1] Higashi T, Shekelle PG, Solomon DH, Knight EL, Roth C, Chang JT, et al. The quality of pharmacologic care for vulnerable older patients. Ann Intern Med. 2004 May 4; 140(9): 714-720. PMid:15126255

[2] SFK. Foundation for Pharmaceutical Statistics. Facts and Figures 2010. 2009 in numbers. 2010; Available from: http://www.sfk.nl/english/2010fandf.pdf/view. Accessed may 23, Accessed 2012.

[3] Gallagher LP. The potential for adverse drug reactions in elderly patients. Appl Nurs Res. 2001 Nov; 14(4): 220-224. PMid:11699025 http://dx.doi.org/10.1053/apnr.2001.26788

[4] Velden van der L, Langdon R, Batenburg R. Supply and demand trends in nursing and care in the Netherlands. A knowledge synthesis of existing literature and data sources. 2011. NIVEL report (in Dutch).

[5] Meredith S, Feldman PH, Frey D, Hall K, Arnold K, Brown NJ, et al. Possible medication errors in home healthcare patients. J Am Geriatr Soc. 2001 Jun; 49(6): 719-724. PMid:11454109 http://dx.doi.org/10.1046/j.1532-5415.2001.49147.x

[6] Parsons C, Lapane K, Kerse N, Hughes C. Prescribing for older people in nursing homes: a review of the key issues. Int J Older People Nurs. 2011 Mar; 6(1): 45-54. PMid:21303465 http://dx.doi.org/10.1111/j.1748-3743.2010.00264.x

[7] Boom van der, H. Home nursing in Europe: Patterns of Professionalisation and Institutionalisation of Home Care and Family Care to Elderly People in Denmark, France, the Netherlands and Germany": a macro-sociological, qualitative study into international differences in home care and informal care for elderly people in four European countries. Thesis. Maastricht University; 2008.

[8] Ndosi ME, Newell R. Nurses' knowledge of pharmacology behind drugs they commonly administer. J Clin Nurs. 2009 Feb; 18(4): 570-80; discussion 620. PMid:18680489 http://dx.doi.org/10.1111/j.1365-2702.2008.02290.x

[9] Bergqvist M, Ulfvarson J, Karlsson EA. Nurse-led medication reviews and the quality of drug treatment of elderly hospitalized patients. Eur J Clin Pharmacol. 2009 Nov; 65(11): 1089-1096. PMid:19798491 http://dx.doi.org/10.1007/s00228-009-0728-2

[10] Lucero RJ, Lake ET, Aiken LH. Nursing care quality and adverse events in US hospitals. J Clin Nurs. 2010 Aug; 19(15-16): 2185-2195. PMid:20659198 http://dx.doi.org/10.1111/j.1365-2702.2010.03250.x

[11] Sulosaari V, Suhonen R, Leino-Kilpi H. An integrative review of the literature on registered nurses' medication competence. J Clin Nurs. 2011 Feb; 20(3-4): 464-478. PMid:20738454 http://dx.doi.org/10.1111/j.1365-2702.2010.03228.x

[12] Arnold GJ. Avoiding inappropriate drug prescribing: fundamental principles for rational medication management. Clin Nurse Spec. 1999 Nov; 13(6): 289-295. PMid:11188565 http://dx.doi.org/10.1097/00002800-199911000-00012

[13] Kovner C, Menezes J, Goldberg JD. Examining nurses' decision process for medication management in home care. Jt Comm J Qual Patient Saf. 2005 Jul; 31(7): 379-385. PMid:16130981

[14] Bandura A. Self-efficacy: toward a unifying theory of behavioral change. Psychol Rev. 1977 Mar; 84(2): 191-215. PMid:847061 http://dx.doi.org/10.1037/0033-295X.84.2.191

[15] Ellenbecker CH, Frazier SC, Verney S. Nurses' observations and experiences of problems and adverse effects of medication management in home care. Geriatr Nurs. 2004 May-Jun; 25(3): 164-170. PMid:15197376 http://dx.doi.org/10.1016/j.gerinurse.2004.04.008

[16] Kunneman H SM. Homecare in Transition. The impact of recent changes for home care organisation. 2007.

[17] Hanrath C. Comeback of the home healthcare nurse. She is back! 2010 May(1381-5911): 30-31,32,33.

[18] Ives G, Hodge K, Bullock S, Marriott J. First year RNs' actual and self-rated pharmacology knowledge. Aust J Adv Nurs. 1996 Sep-Nov; 14(1): 13-19. PMid:9128465

[19] Grandell-Niemi H, Hupli M, Leino-Kilpi H, Puukka P. Finnish nurses' and nursing students' pharmacological skills. J Clin Nurs. 2005 Jul; 14(6): 685-694. PMid:15946276 http://dx.doi.org/10.1111/j.1365-2702.2005.01131.x

[20] Sino CG, Munnik A, Schuurmans MJ. Knowledge and perspectives of Dutch home healthcare nurses regarding medication frequently used by older people. Int J Older People Nurs. 2012 Jul 16. PMid:22805649 http://dx.doi.org/10.1111/j.1748-3743.2012.00336.x

[21] Lim LM, Chiu LH, Dohrmann J, Tan KL. Registered nurses' medication management of the elderly in aged care facilities. Int Nurs Rev. 2010 Mar; 57(1): 98-106. PMid:20487481 http://dx.doi.org/10.1111/j.1466-7657.2009.00760.x

[22] Molony SL. Monitoring medication use in older adults. Am J Nurs. 2009 Jan; 109(1): 68-78; quiz 78-9. PMid:19112274 http://dx.doi.org/10.1097/01.NAJ.0000344046.42145.9d 